\title{
Will multi-parametric magnetic resonance imaging be the future tool to detect clinically significant prostate cancer?
}

\author{
Gianluca Giannarini ${ }^{1}$, Michele Zazzara ${ }^{1}$, Marta Rossanese ${ }^{1}$, Vito Palumbo ${ }^{1}$, Martina Pancot ${ }^{2}$, \\ Giuseppe Como ${ }^{2}$, Maria Abbinante ${ }^{1}$ and Vincenzo Ficarra ${ }^{1}{ }^{*}$ \\ ${ }^{1}$ Department of Experimental and Clinical Medical Sciences, Urology Unit, University of Udine, Udine, Italy \\ ${ }^{2}$ Department of Medical and Biological Sciences, Institute of Diagnostic Radiology, University of Udine, Udine, Italy
}

\section{Edited by:}

Gianluigi Taverna, Humanitas Clinical and Research Center, Italy

Reviewed by:

Brock O'Neil, The University of Utah, USA

Ari Adamy, Santa Casa Hospital, Brazil

\section{*Correspondence.}

Vincenzo Ficarra, Department of

Experimental and Clinical Medical

Sciences, Urology Unit, Academic

Medical Centre Hospital Udine,

University of Udine, Piazzale Santa

Maria della Misericordia 15, Udine

IT-33100, Italy

e-mail: vincenzo.ficarra@unipd.it
Multi-parametric magnetic resonance imaging is an emerging imaging modality for diagnosis, staging, characterization, and treatment planning of prostate cancer. In this report, we reviewed the literature for studies assessing the accuracy of multi-parametric magnetic resonance imaging in detecting clinically significant prostate cancer, and we critically examined the future role of this imaging tool in various clinical diagnostic settings. There is accumulating evidence suggesting a high accuracy of multi-parametric magnetic resonance imaging in ruling out clinically significant disease. Although definition for clinically significant disease widely varies, the negative predictive value is very high at up to $98 \%$. Multi-parametric magnetic resonance imaging should, thus, be further evaluated for application in different clinical scenarios in which it is desirable to reduce the proportion of unnecessary prostate biopsies and to limit the detection of indolent disease, such as opportunistic screening, persistent prostate cancer suspicion in men with previous negative prostate biopsies, and eligibility for active surveillance. Continued improvement in standardization of technical parameters, functional sequences, and image reporting systems is a pre-requisite for a rapid and successful dissemination of this imaging modality.

Keywords: prostate neoplasms, magnetic resonance imaging, prostate biopsy, screening, active surveillance, radical prostatectomy

\section{BACKGROUND}

In one large randomized trial, prostate-cancer $(\mathrm{PCa})$ screening has resulted in a reduction in risk of metastatic disease and cancerspecific mortality (1). However, a major concern of screening is overdiagnosis of cases that would not have caused clinical consequences if left untreated (2). Overdiagnosis, in turn, leads to overtreatment, with the potential for unnecessary side effects related to curative treatments. Strategies to reduce overdiagnosis are mandatory, as are strategies to differentiate indolent from aggressive tumors. Novel biomarkers, such as serum/urine markers (e.g., PSA isoform-based "Prostate Health Index" and PCA3) and advanced imaging techniques (e.g., functional magnetic resonance imaging [MRI]) hold promise for their potential to improve accuracy in detecting clinically significant PCa. However, none of them is ready to be integrated into clinical practice because large-scale validation is lacking.

Owing to its high soft tissue contrast and high resolution, MRI provides a better visualization of the prostate and its lesions compared to transrectal ultrasound (TRUS) and other imaging modalities (3). Over the past years, its use has shifted from staging purpose to that of detection of PCa thanks to refinement in image acquisition protocols and introduction of functional techniques. The availability of higher field strength magnets $(3 \mathrm{~T})$, increased number of phased array receiver coils, and improved pulse-sequence techniques has resulted in a greater signal-tonoise ratio and, thus, increased spatial resolution (4). Moreover, the increasing utilization of so-called "multi-parametric MRI"
(MP-MRI), deriving from the combination of conventional morphological T2-weighted sequences with at least two of the newest functional techniques, i.e., diffusion-weighted imaging (DWI), dynamic contrast-enhanced (DCE) imaging, and magnetic resonance spectroscopic imaging (MRSI), has further improved the capability to locate and characterize prostate lesions (4). DWI quantifies the microscopic mobility of water molecules in the extracellular extravascular space, providing information on cell density. PCa exhibits a reduced diffusion of water compared to normal prostate tissue due to hypercellularity with a relative decrease in water content and to disruption of interstitial spaces through which water normally diffuses. DCE imaging uses a bolus of intravenous gadolinium contrast, followed by a series of rapid sequential scans at short time intervals, to generate maps of tissue perfusion. High-grade tumors typically show an early and intense contrast enhancement followed by a rapid washout. MRSI allows for the assessment of cell metabolism by displaying the relative concentrations of citrate, choline, creatine, and polyamines. Intracellular levels of choline and creatine increase, while those of citrate decrease in malignant lesions, and are associated with tumor volume and grade (4).

Due to these peculiarities, MP-MRI has been studied in various clinical settings:

- Opportunistic screening.

- Selecting men for repeat prostate biopsy.

- Informing/guiding prostate biopsy. 

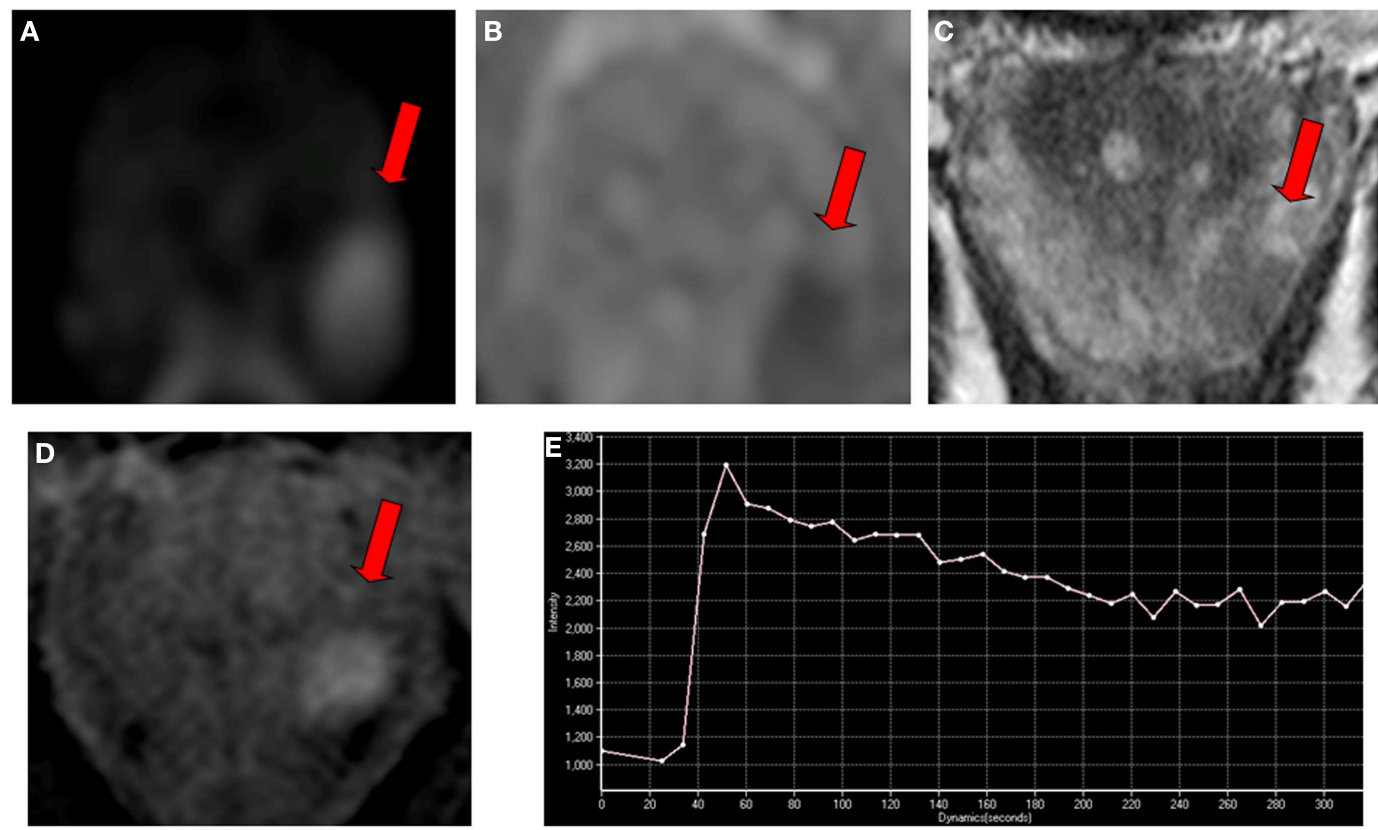

FIGURE 1 | Multi-parametric magnetic resonance imaging in a 65-year-old man referred for early detection of prostate cancer with an elevated serum PSA level $(7 \mathrm{ng} / \mathrm{ml})$ and a normal digital rectal examination. Magnetic resonance imaging consisted of conventional T2-weighted, diffusion-weighted, and dynamic contrast-enhanced sequences performed on a 3T unit without endorectal coil. (A) An ovoidal hyperintense lesion (arrow) was observed on axial diffusion-weighted imaging at $b$-value $1000 \mathrm{~s} / \mathrm{mm}^{2}$ in left apical peripheral zone. (B) The lesion (arrow) corresponded to hypointense lesion on apparent diffusion coefficient map. (C) The lesion (arrow) also corresponded to axial T2-weighted image with low signal intensity, and to (D) focal enhanced lesion on axial dynamic contrast-enhanced imaging with a type 3 enhancement curve (washout) (E). The final Prostate Imaging Reporting and Data System score for this lesion was four. The presence of a clinically significant cancer was confirmed with a targeted biopsy, showing an 8-mm Gleason score $4+3$ adenocarcinoma.
- Selecting men for active surveillance.

- Monitoring tumour progression during active surveillance.

- Clinical staging.

- Treatment selection.

- Surgical planning (e.g., nerve-sparing radical prostatectomy).

- Focal therapy planning.

- Radiation therapy planning.

In two recent review articles, the use of MP-MRI-derived targets to guide biopsy has been shown to significantly improve PCa detection over systematic TRUS-guided prostate biopsy (PB), with sensitivity rates up to $80 \%$ for cancers located in the peripheral zone $(5,6)$. In fact, accurate lesion localization with MP-MRI enables a targeted biopsy, which overcomes the limitations inherent to the conventional systematic TRUS-guided PB, such as sampling error and undersampling of poorly accessible prostate regions (e.g., anterior gland). This high diagnostic performance is particularly evident in the setting of repeat $\mathrm{PB}$ after previous negative systematic TRUS-guided PB, where cancer is detected in up to $63 \%$ of patients using MRI-guidance, with up to $87 \%$ of these cancers qualifying as clinically significant (6). In addition, accumulating data suggest that the newest functional sequences, particularly DWI where a quantitative image analysis is possible, have the ability to differentiate between low- and intermediate-/highgrade tumors, at least for those cancers located in the peripheral zone $(7,8)$.
In an attempt to standardize the reporting of MP-MRI, in 2012 an expert panel of the European Society of Urogenital Radiology (ESUR) introduced the Prostate Imaging Reporting and Data System (PI-RADS) as part of the MRI guidelines for prostate imaging (9). According to this semi-objective scoring system, each suspicious prostate lesion is assigned a point between one and five for each sequence performed as part of MP-MRI, with one being most likely clinically non-significant and five being most likely clinically significant disease. Figure 1 shows an example of clinically significant disease.

Based on all these premises, MP-MRI is a strong candidate tool for the detection of aggressive $\mathrm{PCa}$, with the potential to reduce the number of unnecessary biopsies and the rate of overdetection and overtreatment.

Thus, the aim of this report is to review the literature for studies assessing the accuracy of MP-MRI in detecting clinically significant $\mathrm{PCa}$, and to critically examine the future role of this imaging tool in various clinical diagnostic settings.

\section{MULTI-PARAMETRIC MRI AND CLINICALLY SIGNIFICANT PROSTATE-CANCER: LITERATURE EVIDENCE}

Although there is agreement that detection of "clinically significant disease" should be the primary aim of any diagnostic tool for $\mathrm{PCa}$, no consensus on its definition has been reached (10). From a methodological standpoint, this is a major obstacle to assess this outcome measure in a proper and systematic manner. 
Several studies are available that have been designed to address the question as to whether MP-MRI is able to in detecting "clinically significant disease." In this non-systematic mini-review, we present only those series reporting full data on diagnostic accuracy (11-16). Details of the six included studies are reported in Table 1. Of them, four were prospective and two retrospective cohort studies. Included were patients undergoing both initial and repeat PB with varying PSA ranges. Only in one study (12), there was also a minority of men already diagnosed with low-risk PCa. Histology at PB was the reference standard in all studies. Different modalities for $\mathrm{PB}$ were used, ranging from transperineal template mapping to TRUS-guided sampling using cognitive or visual registration of the MRI target or registration software fusing MRI images with real-time TRUS. In addition, MP-MRI protocols and image acquisitions were not uniform, as well as statistical methods of analysis. Finally, four studies $(11,12,14,15)$ originated from the same researchers' group, introducing a possible publication bias.

Due to all these reasons, the performance of MP-MRI in detecting "clinically significant disease" varied considerably across the studies. Accuracy, positive predictive value and negative predictive value ranged from 23 to $80 \%, 6$ to $82 \%$, and 47 to $100 \%$, respectively (Table 1). It is notable, however, that the negative predictive value, albeit decreasing with higher thresholds for the definition of "clinically significant disease," remained relatively high, implying that MP-MRI is a reliable tool to rule out potentially aggressive tumors.

\section{CURRENT CHALLENGES OF MULTI-PARAMETRIC MRI IN DETECTING CLINICALLY SIGNIFICANT PROSTATE CANCER}

The ESUR PI-RADS is based on opinion of experts, is currently undergoing changes and refinements and still awaits a formal validation (17). Such validation study should include a design where MP-MRI is performed prior to $\mathrm{PB}$, several readers blinded to clinical data and with different experience in prostate MP-MRI evaluate independently the images, MRI-targeted PB is compared to systematic TRUS-guided PB, and the reference standard is final pathology of radical prostatectomy specimens with and without preoperatively known PCa so as to reduce the bias in which readers are aware that the study population comprises only patients with proven PCa. To the best of our knowledge, only a single diagnostic study on MRI used final pathology of prostates with and without cancer as the reference standard, having enrolled patients eventually treated with RP or radical cystectomy (18). This study, however, was not powered to address the issue of false positives with only 18 patients with no PCa. Moreover, only DW sequences were used. Thus, a refinement of the existing semi-objective scoring systems with focus on clinically significant disease is warranted.

Moreover, the accuracy of image reporting is strongly dependent on reader expertise. Taken the results of two recent studies in aggregate $(19,20)$, subjective scoring (so-called Likert scales) by experienced readers results in more accurate characterization of the likelihood of malignancy of prostate lesions seen at MPMRI than do the semi-objective scores, such as the PI-RADS and morphology-location-signal intensity scale. It is reasonable to think that this is also the case for the characterization of clinically significant disease.
In order to disseminate in the clinical practice, MP-MRI should be standardized not only with regard to image reporting systems, but also with regard to technical equipment, examination protocols, and image acquisition, processing and postprocessing. Moreover, future studies should always assess interobserver variability among expert and junior readers, and learning curve for both MP-MRI readers and operators performing MRI-informed PB (if different from readers). Communication between low-volume centers and high-volume centers should be promoted with training programs and tele-courses. Clinically significant disease should be the primary outcome measure in such studies.

Furthermore, histology parameters available at MRI-targeted biopsy may not necessarily have the same value of those available at systematic TRUS-guided PB. With the former, there is typically an upgrade in Gleason score and a higher percentage of cancer per core compared to the latter. Therefore, a new definition of "clinically significant disease" will be required. Validation of these "new" risk parameters is mandatory to determine the true value of pre-biopsy MRI.

In addition, whether MRI-targeted biopsies should be always complemented by systematic TRUS-guided PB during first and repeat $\mathrm{PB}$ setting remains unknown. When transperineal saturation biopsy is set as the reference standard, approximately $10 \%$ of men with "negative" MP-MRI performed by experienced highvolume radiologists still harbor intermediate-risk disease (21). It is plausible that with increasing precision in MRI-targeted biopsy technology, systematic biopsies will lose their value.

Finally, costs related to this sophisticated imaging technology are still an issue for many radiological centers worldwide. A formal cost-effectiveness analysis is eagerly awaited.

THE FUTURE DIAGNOSTIC ROLE OF MULTI-PARAMETRIC MRI Based on the relatively high negative predictive value for "clinically significant disease," it might not be impossible for MP-MRI to become a first-line screening tool. This would entail a major paradigm shift in PCa. By optimizing diagnosis, and subsequently preventing overtreatment of clinically insignificant disease, MPMRI-informed PB may provide a method for streamlining the diagnostic pathway in $\mathrm{PCa}$. A recent prospective trial in $\mathrm{PB}-$ naïve men has provided promising results with this regard (22). Compared to systematic TRUS-guided PB, a diagnostic pathway including MP-MRI and selective MP-MRI-guided biopsy of equivocal or suspicious lesions reduced the need for biopsy by $51 \%$, decreased the diagnosis of low-risk PCa by $89.4 \%$, and increased the detection of intermediate/high-risk PCa by $17.7 \%$.

With increasing adoption of scanners with higher strength fields (i.e., $3 \mathrm{~T}$ ) ensuring a better image quality without an endorectal coil, patient acceptance is expected to increase. On the other hand, it remains to be proven whether DCE-MRI has an additional diagnostic value compared to DW-MRI with conventional T2-weighted MRI, particularly for the detection of significant disease (23). Furthermore, the use of MRSI is decreasing because it requires an endorectal coil even using high strength fields, complex software, a longer training to achieve proficient image interpretation and a long reading time. If DW-MRI alone combined with conventional T2-weighted MRI would prove to be 
Table 1 | Main characteristics of the selected studies evaluating multi-parametric magnetic resonance imaging in detecting clinically significant prostate cancer and reporting full data on diagnostic accuracy.

\begin{tabular}{|c|c|c|c|c|c|c|c|c|c|c|c|c|}
\hline \multirow[t]{2}{*}{$\begin{array}{l}\text { First author } \\
\text { [reference] }\end{array}$} & \multirow[t]{2}{*}{$N$} & \multirow[t]{2}{*}{$\begin{array}{l}\text { Study } \\
\text { design }\end{array}$} & \multirow[t]{2}{*}{$\begin{array}{l}\text { Prostate biopsy } \\
\text { status }\end{array}$} & \multirow[t]{2}{*}{ Reference standard } & \multirow{2}{*}{$\begin{array}{l}\text { Level of analysis } \\
\text { for MP-MRI } \\
\text { performance }\end{array}$} & \multirow{2}{*}{$\begin{array}{l}\text { Overall } \\
\text { cancer } \\
\text { detection } \\
\text { rate }(\%)\end{array}$} & \multirow[t]{2}{*}{$\begin{array}{l}\text { Definition of clinically } \\
\text { significant cancer }\end{array}$} & \multicolumn{5}{|c|}{$\begin{array}{l}\text { Diagnostic performance of MP-MRI for } \\
\text { clinically significant cancer }\end{array}$} \\
\hline & & & & & & & & Acc (\%) & Sen $(\%)$ & Spe (\%) & PPV (\%) & NPV (\%) \\
\hline Rouse (11) & 114 & $P$ & Biopsy-naïve & $\begin{array}{l}\text { Systematic + targeted } \\
\text { (cognitive) US-guided } \\
\text { transrectal biopsy }\end{array}$ & Whole prostate & 60 & $\begin{array}{l}\mathrm{GS} \geq 7 \text { and maximum } \\
\mathrm{CCL} \geq 3 \mathrm{~mm} \\
\mathrm{GS} \geq 7 \text { and maximum } \\
\mathrm{CCL} \geq 5 \mathrm{~mm}\end{array}$ & $\begin{array}{l}64 \\
61.4\end{array}$ & $\begin{array}{l}91.5 \\
92.9\end{array}$ & $\begin{array}{l}44.8 \\
43.1\end{array}$ & $\begin{array}{l}53.8 \\
48.8\end{array}$ & $\begin{array}{l}88.2 \\
91.2\end{array}$ \\
\hline $\begin{array}{l}\text { Arumainayagam } \\
(12)^{a}\end{array}$ & 64 & $\mathrm{R}$ & $\begin{array}{l}\text { Biopsy- } \\
\text { naïve + previous } \\
\text { negative } \\
\text { biopsy + previous } \\
\text { positive biopsy }\end{array}$ & TPMB & $\begin{array}{l}\text { Whole } \\
\text { prostate/prostate } \\
\text { halves }^{c}\end{array}$ & 84 & $\begin{array}{l}\text { UCL2 criteria } \\
\text { UCL1 criteria } \\
\text { Goto's criteria } \\
\text { Epstein's criteria } \\
\text { GS } \geq 7\end{array}$ & $\begin{array}{l}72 / 74 / 72 \\
64 / 65 / 61 \\
73 / 79 / 80 \\
73 / 79 / 77 \\
75 / 73 / 66\end{array}$ & $\begin{array}{l}88 / 90 / 95 \\
88 / 88 / 94 \\
83 / 87 / 94 \\
85 / 89 / 94 \\
100 / 97 / 100\end{array}$ & $\begin{array}{l}44 / 48 / 30 \\
37 / 38 / 23 \\
44 / 56 / 38 \\
44 / 56 / 33 \\
48 / 47 / 29\end{array}$ & $\begin{array}{l}74 / 75 / 71 \\
61 / 62 / 58 \\
82 / 85 / 82 \\
80 / 83 / 78 \\
67 / 66 / 60\end{array}$ & $\begin{array}{l}67 / 73 / 78 \\
73 / 73 / 78 \\
47 / 60 / 67 \\
53 / 67 / 67 \\
100 / 93 / 100\end{array}$ \\
\hline $\begin{array}{l}\text { Rais-Bahrami } \\
(13)^{\mathrm{b}}\end{array}$ & 583 & $P$ & Biopsy-naïve & $\begin{array}{l}\text { Systematic + targeted } \\
\text { (MRI/US } \\
\text { fusion-guided) } \\
\text { transrectal biopsy }\end{array}$ & Whole prostate & 54 & $\begin{array}{l}\mathrm{GS} \geq 7 \\
\mathrm{GS} \geq 8\end{array}$ & $\begin{array}{l}\text { NA } \\
\text { NA }\end{array}$ & $\begin{array}{l}94 / 33 \\
98 / 45\end{array}$ & $\begin{array}{l}28 / 92 \\
24 / 89\end{array}$ & $\begin{array}{l}38 / 67 \\
18 / 41\end{array}$ & $\begin{array}{l}91 / 75 \\
91 / 91\end{array}$ \\
\hline $\begin{array}{l}\text { Abd-Alazeez } \\
(14)^{\mathrm{b}}\end{array}$ & 129 & $\mathrm{R}$ & Biopsy naïve & TPMB & Prostate halves & 55 & $\begin{array}{l}U C L 2 \text { criteria } \\
U C L 1 \text { criteria } \\
G S \geq 4+3 \\
G S \geq 3+4 \\
\text { maximum } C C L \geq 6 \mathrm{~mm} \\
\text { maximum } C C L \geq 4 \mathrm{~mm}\end{array}$ & $\begin{array}{l}44 / 68 \\
42 / 67 \\
23 / 62 \\
36 / 66 \\
33 / 67 \\
40 / 68\end{array}$ & $\begin{array}{l}94 / 68 \\
98 / 81 \\
100 / 92 \\
93 / 70 \\
98 / 80 \\
94 / 81\end{array}$ & $\begin{array}{l}23 / 69 \\
22 / 66 \\
19 / 61 \\
21 / 65 \\
21 / 65 \\
22 / 67\end{array}$ & $\begin{array}{l}34 / 48 \\
21 / 34 \\
6 / 11 \\
24 / 35 \\
19 / 30 \\
28 / 42\end{array}$ & $\begin{array}{l}89 / 83 \\
98 / 94 \\
100 / 99 \\
92 / 89 \\
98 / 95 \\
91 / 88\end{array}$ \\
\hline $\begin{array}{l}\text { Abd-Alazeez } \\
(15)^{\mathrm{b}}\end{array}$ & 54 & $P$ & $\begin{array}{l}\text { Previous negative } \\
\text { biopsy }\end{array}$ & TPMB & Prostate halves & 63 & $\begin{array}{l}U C L 2 \text { criteria } \\
U C L 1 \text { criteria } \\
G S \geq 4+3 \\
G S \geq 3+4 \\
\text { maximum } C C L \geq 6 \mathrm{~mm} \\
\text { maximum } C C L \geq 4 \mathrm{~mm}\end{array}$ & $\begin{array}{l}53 / 80 \\
51 / 70 \\
41 / 71 \\
52 / 79 \\
49 / 78 \\
48 / 75\end{array}$ & $\begin{array}{l}76 / 67 \\
90 / 80 \\
100 / 79 \\
87 / 74 \\
89 / 77 \\
74 / 62\end{array}$ & $\begin{array}{l}42 / 85 \\
42 / 80 \\
38 / 71 \\
42 / 80 \\
41 / 78 \\
39 / 79\end{array}$ & $\begin{array}{l}38 / 67 \\
26 / 47 \\
7 / 12 \\
29 / 50 \\
23 / 41 \\
29 / 49\end{array}$ & $\begin{array}{l}79 / 85 \\
95 / 94 \\
100 / 99 \\
92 / 92 \\
95 / 94 \\
82 / 86\end{array}$ \\
\hline
\end{tabular}


Table 1 | Continued

\begin{tabular}{|c|c|c|c|c|c|c|c|c|c|c|c|c|}
\hline \multirow[t]{2}{*}{$\begin{array}{l}\text { First author } \\
\text { [reference] }\end{array}$} & \multirow[t]{2}{*}{$N$} & \multirow[t]{2}{*}{$\begin{array}{l}\text { Study } \\
\text { design }\end{array}$} & \multirow[t]{2}{*}{$\begin{array}{l}\text { Prostate biopsy } \\
\text { status }\end{array}$} & \multirow[t]{2}{*}{ Reference standard } & \multirow{2}{*}{$\begin{array}{l}\text { Level of analysis } \\
\text { for MP-MRI } \\
\text { performance }\end{array}$} & \multirow{2}{*}{$\begin{array}{l}\text { Overall } \\
\text { cancer } \\
\text { detection } \\
\text { rate }(\%)\end{array}$} & \multirow[t]{2}{*}{$\begin{array}{l}\text { Definition of clinically } \\
\text { significant cancer }\end{array}$} & \multicolumn{5}{|c|}{$\begin{array}{l}\text { Diagnostic performance of MP-MRI for } \\
\text { clinically significant cancer }\end{array}$} \\
\hline & & & & & & & & Acc (\%) & Sen $(\%)$ & Spe $(\%)$ & PPV (\%) & NPV (\%) \\
\hline \multirow[t]{4}{*}{ Thompson (16) } & 150 & $\mathrm{P}$ & Biopsy-naïve & TPMB + targeted & Whole prostate & 61 & $\mathrm{GS} \geq 7$ & NA & 94 & 50 & 52 & 94 \\
\hline & & & & $\begin{array}{l}\text { (cognitive) US-guided } \\
\text { transperineal biopsy }\end{array}$ & & & $\begin{array}{l}\mathrm{GS} \geq 7 \text { with }>5 \% \\
\text { Gleason grade } 4\end{array}$ & & 96 & 47 & 43 & 96 \\
\hline & & & & & & & $\begin{array}{l}\mathrm{GS} \geq 6 \text { with } \geq 20 \% \\
\text { positive cores or } \\
\text { maximum } \mathrm{CCL} \geq 5 \mathrm{~mm}\end{array}$ & & 93 & 53 & 58 & 92 \\
\hline & & & & & & & $\begin{array}{l}\mathrm{GS} \geq 6 \text { with }>5 \% \\
\text { Gleason grade } 4, \geq 30 \% \\
\text { positive cores or } \\
\text { maximum } \mathrm{CCL} \geq 8 \mathrm{~mm}\end{array}$ & & 96 & 50 & 50 & 96 \\
\hline
\end{tabular}

Acc, accuracy; CCL, cancer core length; Epstein's criteria, Gleason score $\geq 7$ or PSA density $\geq 0.1 \mathrm{ng} / \mathrm{ml} / \mathrm{g}$ or $\geq 3$ positive cores or $\geq 1$ biopsy core with $>50 \%$ involvement; Goto's criteria, Gleason score $\geq 7$ or maximum cancer core length $\geq 2 \mathrm{~mm} ; G S$, Gleason score; MRI, magnetic resonance imaging; MP-MRI, multi-parametric magnetic resonance imaging; NA, not available; NPV, negative predictive value; , prospective; PPV, positive predictive value; $R$, retrospective; Sen, sensitivity; Spe, specificity; TPMB, transperineal prostate mapping biopsy; UCL 1, University College of London definition 1 (Gleason score $\geq 4+3$ and/or maximum cancer core length $\geq 6 \mathrm{~mm}$ and/or total cancer core length $\geq 6 \mathrm{~mm}$ ); UCL2, University College of London definition 2 (Gleason score $\geq 3+4$ and/or maximum cancer core length $\geq 4 \mathrm{~mm}$ and/or total cancer core length $\geq 6 \mathrm{~mm}) ; \mathrm{US}$, ultrasound.

aThree independent multi-parametric magnetic resonance imaging readers.

${ }^{b}$ Two different thresholds for clinically significant cancer suspicion at multi-parametric magnetic resonance imaging.

${ }^{c}$ Only data on whole prostate level analysis are reported. 
sufficiently accurate as a biparametric technique, the advantages would be numerous. Compared to the other functional techniques, in fact, DW-MRI requires no contrast medium administration, no special software for image analysis, and no particular experience in image interpretation. Moreover, image analysis is faster and less expensive, and quantitative data can be used to predict PCa grading. Therefore, this biparametric technique could be applied to broader clinical settings, including larger patient populations, such as those for screening and early detection programs.

Active surveillance (AS) is an emerging treatment option for most low- and some intermediate-risk PCa patients with the aim of reducing overtreatment of indolent disease. Eligibility criteria in all representative AS protocols are based on standard clinico-pathological variables, which are inaccurate to predict "clinically significant disease." The risk of misclassification is, thus, a major problem. With this regard, MP-MRI could be a useful tool both to determine initial eligibility for AS and to monitor disease progression. MP-MRI performed early after an initial standard TRUS-guided PB suggesting histological suitability for AS could exclude immediately those misclassified patients (approximately 30\%) with "clinically significant disease" (24). However, it remains to be determined whether the adoption of a MP-MRI-based pathway with targeted PB is superior to, e.g., a systematic saturation $\mathrm{PB}$ as a reclassification tool at entry in AS protocols, the latter being clearly less expensive. Identifying tumor progression during AS is also a major challenge, given the inaccuracy of the standard clinical and histological parameters. MP-MRI could then significantly reduce the number of unnecessary surveillance biopsies, thereby making AS less invasive. Unfortunately, there is no currently accepted definition of "radiological" progression. It is likely that this will be based both on morphological parameters (e.g., lesion size/volume) and functional parameters (e.g., changes in qualitative and quantitative parameters derived from functional sequences such as DWI and DCE).

\section{CONCLUSION}

MP-MRI is an emerging imaging modality for diagnosis, staging, characterization, and treatment planning of PCa. There is accumulating evidence suggesting a high accuracy of MP-MRI in ruling out "clinically significant disease." MP-MRI should, thus, be further evaluated for application in different clinical scenarios in which it is desirable to reduce the proportion of unnecessary PBs and to limit the detection of indolent disease, such as opportunistic screening, persistent PCa suspicion in men with previous negative $\mathrm{PB}$, and eligibility for AS. Continued improvement in standardization of technical parameters, functional sequences, and image reporting systems is a pre-requisite for a rapid and successful dissemination of this imaging modality.

\section{REFERENCES}

1. Schröder FH, Hugosson J, Roobol MJ, Tammela TL, Ciatto S, Nelen V, et al. Prostate-cancer mortality at 11 years of follow-up. N Engl J Med (2012) 366:981-90. doi:10.1056/NEJMoa1113135

2. Loeb S, Bjurlin MA, Nicholson J, Tammela TL, Penson DF, Carter HB, et al. Overdiagnosis and overtreatment of prostate cancer. Eur Urol (2014) 65:1046-55. doi:10.1016/j.eururo.2013.12.062
3. Yacoub JH, Oto A, Miller FH. MR imaging of the prostate. Radiol Clin North Am (2014) 52:811-37. doi:10.1016/j.rcl.2014.02.010

4. Thompson J, Lawrentschuk N, Frydenberg M, Thompson L, Stricker P; USANZ. The role of magnetic resonance imaging in the diagnosis and management of prostate cancer. BJU Int (2013) 112(Suppl 2):6-20. doi:10.1111/bju. 12381

5. Moore CM, Robertson NL, Arsanious N, Middleton T, Villers A, Klotz L, et al. Image-guided prostate biopsy using magnetic resonance imaging-derived targets: a systematic review. Eur Urol (2013) 63:125-40. doi:10.1016/j.eururo.2012. 06.004

6. Bjurlin MA, Meng X, Le Nobin J, Wysock JS, Lepor H, Rosenkrantz AB, et al. Optimization of prostate biopsy: the role of magnetic resonance imaging targeted biopsy in detection, localization and risk assessment. J Urol (2014) 192:648-58. doi:10.1016/j.juro.2014.03.117

7. Peng Y, Jiang Y, Yang C, Brown JB, Antic T, Sethi I, et al. Quantitative analysis of multiparametric prostate MR images: differentiation between prostate cancer and normal tissue and correlation with Gleason score - a computer-aided diagnosis development study. Radiology (2013) 267:787-96. doi:10.1148/radiol. 13121454

8. Donati OF, Afaq A, Vargas HA, MazaheriY, Zheng J, Moskowitz CS, et al. Prostate MRI: evaluating tumor volume and apparent diffusion coefficient as surrogate biomarkers for predicting tumor Gleason score. Clin Cancer Res (2014) 20:3705-11. doi:10.1158/1078-0432.CCR-14-0044

9. Barentsz JO, Richenberg J, Clements R, Choyke P, Verma S, Villeirs G, et al. ESUR prostate MR guidelines 2012. Eur Radiol (2012) 22:746-57. doi:10.1007/s00330011-2377-y

10. Ploussard G, Epstein JI, Montironi R, Carroll PR, Wirth M, Grimm MO, et al. The contemporary concept of significant versus insignificant prostate cancer. Eur Urol (2011) 60:291-303. doi:10.1016/j.eururo.2011.05.006

11. Rouse P, Shaw G, Ahmed HU, Freeman A, Allen C, Emberton M. Multiparametric magnetic resonance imaging to rule-in and rule-out clinically important prostate cancer in men at risk: a cohort study. Urol Int (2011) 87:49-53. doi:10.1159/000325880

12. Arumainayagam N, Ahmed HU, Moore CM, Freeman A, Allen C, Sohaib SA, et al. Multiparametric MR imaging for detection of clinically significant prostate cancer: a validation cohort study with transperineal template prostate mapping as the reference standard. Radiology (2013) 268:761-9. doi:10.1148/radiol. 13120641

13. Rais-Bahrami S, Siddiqui MM, Turkbey B, Stamatakis L, Logan J, Hoang AN, et al. Utility of multiparametric magnetic resonance imaging suspicion levels for detecting prostate cancer. J Urol (2013) 190:1721-7. doi:10.1016/j.juro.2013. 05.052

14. Abd-Alazeez M, Kirkham A, Ahmed HU, Arya M, Anastasiadis E, Charman SC, et al. Performance of multiparametric MRI in men at risk of prostate cancer before the first biopsy: a paired validating cohort study using template prostate mapping biopsies as the reference standard. Prostate Cancer Prostatic Dis (2014) 17:40-6. doi:10.1038/pcan.2013.43

15. Abd-Alazeez M, Ahmed HU, Arya M, Charman SC, Anastasiadis E, Freeman A, et al. The accuracy of multiparametric MRI in men with negative biopsy and elevated PSA level - can it rule out clinically significant prostate cancer? Urol Oncol (2014) 32:45.e17-22. doi:10.1016/j.urolonc.2013.06.007

16. Thompson JE, Moses D, Shnier R, Brenner P, Delprado W, Ponsky L, et al. Multiparametric magnetic resonance imaging guided diagnostic biopsy detects significant prostate cancer and could reduce unnecessary biopsies and over detection: a prospective study. J Urol (2014) 192:67-74. doi:10.1016/j.juro.2014.01.014

17. Bomers JG, Barentsz JO. Standardization of multiparametric prostate MR imaging using PI-RADS. Biomed Res Int (2014) 2014:431680. doi:10.1155/2014/ 431680

18. Bains LJ, Studer UE, Froehlich JM, Giannarini G, Triantafyllou M, Fleischmann A, et al. Diffusion-weighted magnetic resonance imaging detects significant prostate cancer with high probability. J Urol (2014) 192:737-42. doi:10.1016/j.juro.2014.03.039

19. Rosenkrantz AB, Lim RP, Haghighi M, Somberg MB, Babb JS, Taneja SS. Comparison of interreader reproducibility of the prostate imaging reporting and data system and likert scales for evaluation of multiparametric prostate MRI. AJR Am J Roentgenol (2013) 201:W612-8. doi:10.2214/AJR.12.10173

20. Vaché T, Bratan F, Mège-Lechevallier F, Roche S, Rabilloud M, Rouvière O. Characterization of prostate lesions as benign or malignant at multiparametric 
MR imaging: comparison of three scoring systems in patients treated with radical prostatectomy. Radiology (2014) 272:446-55. doi:10.1148/radiol. 14131584

21. Kuru TH, Roethke MC, Seidenader J, Simpfendörfer T, Boxler S, Alammar K, et al. Critical evaluation of magnetic resonance imaging targeted, transrectal ultrasound guided transperineal fusion biopsy for detection of prostate cancer. J Urol (2013) 190:1380-6. doi:10.1016/j.juro.2013.04.043

22. Pokorny MR, de Rooij M, Duncan E, Schröder FH, Parkinson R, Barentsz JO, et al. Prospective study of diagnostic accuracy comparing prostate cancer detection by transrectal ultrasound-guided biopsy versus magnetic resonance (MR) imaging with subsequent MR-guided biopsy in men without previous prostate biopsies. Eur Urol (2014) 66:22-9. doi:10.1016/j.eururo.2014.03.002

23. Haghighi M, Shah S, Taneja SS, Rosenkrantz AB. Prostate cancer: diffusionweighted imaging versus dynamic-contrast enhanced imaging for tumor localization-a meta-analysis. J Comput Assist Tomogr (2013) 37:980-8. doi:10. 1097/RCT.0b013e3182a3f9c7

24. Moore CM, Ridout A, Emberton M. The role of MRI in active surveillance of prostate cancer. Curr Opin Urol (2013) 23:261-7. doi:10.1097/MOU. ob013e32835f899f
Conflict of Interest Statement: The authors declare that the research was conducted in the absence of any commercial or financial relationships that could be construed as a potential conflict of interest.

Received: 30 July 2014; accepted: 08 October 2014; published online: 04 November 2014.

Citation: Giannarini G, Zazzara M, Rossanese M, Palumbo V, Pancot M, Como G, Abbinante Mand Ficarra $V$ (2014) Will multi-parametric magnetic resonance imaging be the future tool to detect clinically significant prostate cancer? Front. Oncol. 4:294. doi: 10.3389/fonc.2014.00294

This article was submitted to Genitourinary Oncology, a section of the journal Frontiers in Oncology.

Copyright (C) 2014 Giannarini, Zazzara, Rossanese, Palumbo, Pancot, Como, Abbinante and Ficarra. This is an open-access article distributed under the terms of the Creative Commons Attribution License (CC BY). The use, distribution or reproduction in other forums is permitted, provided the original author(s) or licensor are credited and that the original publication in this journal is cited, in accordance with accepted academic practice. No use, distribution or reproduction is permitted which does not comply with these terms. 